\title{
Poor Little Butterfly
}

Poor little Butterfly with wings broken, asleep on the ground. Your life in the balance, so soon after leaving the cocoon. Poor little Butterfly, the cause of your illness hasn't been found. Let your hope not be squashed on this dark afternoon.

Twenty of us, observe you asleep, at peace on the bed. Poor little Butterfly, your wings are clipped, no one knows why. Poor little Butterfly, you are so small compared to the tubes near your head. And now you will be caged in the grey indoors, not the blue sky.

Your small broken body, cut by the knife.

Wings so fragile, you wonder how in the wind they don't tear. It's funny, dear Butterfly, we wound to give life.

Yet tears fall when we cut through skin that's barely there.

You can't see how much we care for a Butterfly we have just met.

I read about broken butterflies and how they face pain.

Dear Butterfly, your face I will not forget.

As indoors it starts to rain.

You are too young, to suffer as much as you have, no words are right.

To calm you, to help you, to applaud you for the fight.

And although your time here was really quite fleeting.

Poor little Butterfly, for eternity, I'll remember this meeting.

\section{Jamie D'Costa}

Correspondence to Jamie D'Costa, College of Medical and Dental Sciences, Birmingham Medical School, Birmingham, UK; jjd249@student.bham.ac.uk

Competing interests None.

Provenance and peer review Not commissioned; externally peer reviewed.

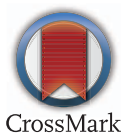

To cite D'Costa J. Med Humanit 2017;43:e7.

Published Online First 21 October 2016

Med Humanit 2017:43:e7. doi:10.1136/medhum-2016-011098 